\title{
Transradial peripheral vascular intervention using Fowler's position and Terumo R2P system for patients with heart failure: two case reports
}

\author{
Akihiro Nakamura*, Kenjiro Sato and Hideaki Endo
}

\begin{abstract}
Background: Positioning a patient on the catheterization table is important for proper cardiac or respiratory function during peripheral vascular interventions. Fowler's position, where the patient's head is a $45^{\circ}$ angle, is more effective in reducing venous blood volume returning to the heart from the periphery compared with the supine position. The Terumo R2P system has been developed for transradial peripheral vascular interventions.

Case presentation: Two patients with heart failure (a 75-year-old Japanese female and a 74-year-old Japanese male) underwent lower-extremity peripheral vascular interventions in Fowler's position to prevent worsening heart failure. Because their head position was opposite the C-arm of the X-ray machine, the left radial artery was selected as the access site. The Terumo R2P system was used for transradial peripheral vascular intervention. We successfully treated superficial artery diseases with long shaft balloons and rapid-exchange Terumo R2P Misago stents.

Conclusions: Although lower-extremity peripheral vascular intervention using Fowler's position and the Terumo R2P system has several limitations, including device availability and technical complexity, it may be effective for particular patients who have higher risk of worsening heart failure in the supine position.
\end{abstract}

Keywords: Fowler's position, Peripheral artery disease, R2P, Transradial intervention, Vac-Lok

\section{Introduction}

Fowler's position, in which the patient's head is placed at a $45^{\circ}$ angle to the table, is often used to accommodate patients comfortably [1]. This position reduces central fluid volume due to decreased venous return from the periphery, which prevents worsening heart failure (HF) [2]. Although peripheral vascular interventions (PVIs) are typically done in the supine position, Fowler's position can be helpful for HF patients with peripheral arterial disease (PAD) because it decreases the ventricular preload. Herein, we report two PAD cases with HF who underwent lower extremity PVI using Fowler's position

*Correspondence: AkihiroNakamura0223@msn.com Department of Cardiology, Iwate Prefectural Central Hospital, 1-4-1, Ueda, Morioka, Iwate 020-0066, Japan and the Terumo R2P system, which has been developed for transradial PVI [3].

\section{Case presentation}

Each patient was initially put in the supine position on the catheterization table with a Vac-Lok fixation device (CIVCO Medical Solutions, Orange City, IA), opposite from the $\mathrm{C}$-arm of the X-ray machine (Fig. 1a) [4]. As shown in Fig. 1b, the left radial artery (RA) was selected as the vessel access site with the R2P system (Terumo, Tokyo, Japan). This device has been developed and specialized for treatment of lower-extremity PAD via radial access [3]. A sheath was inserted into the left RA, either a 7 Fr 16-cm long R2P Glidesheath ${ }^{\circledR}$ slender sheath (Terumo, Tokyo, Japan) or a 6 Fr 119- or 149-cm long R2P Destination slender sheath (Terumo, Tokyo, Japan). The 7 Fr R2P Glidesheath slender sheath has a thin-walled layer, original author(s) and the source, provide a link to the Creative Commons licence, and indicate if changes were made. The images or other third party material in this article are included in the article's Creative Commons licence, unless indicated otherwise in a credit line to the material. If material is not included in the article's Creative Commons licence and your intended use is not permitted by statutory regulation or exceeds the permitted use, you will need to obtain permission directly from the copyright holder. To view a copy of this licence, visit http://creativecommons.org/licenses/by/4.0/. The Creative Commons Public Domain Dedication waiver (http://creativeco mmons.org/publicdomain/zero/1.0/) applies to the data made available in this article, unless otherwise stated in a credit line to the data. 
(a)

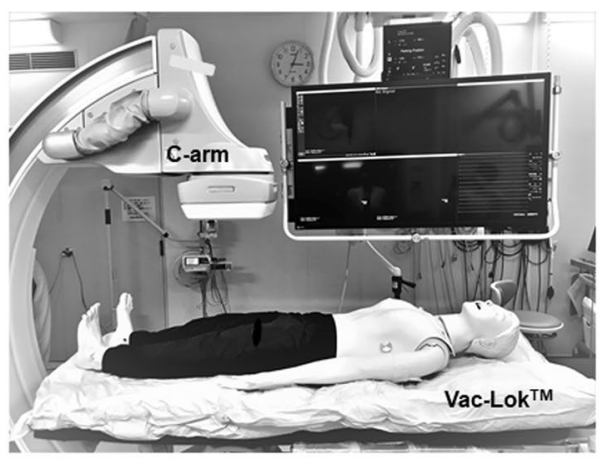

(c)

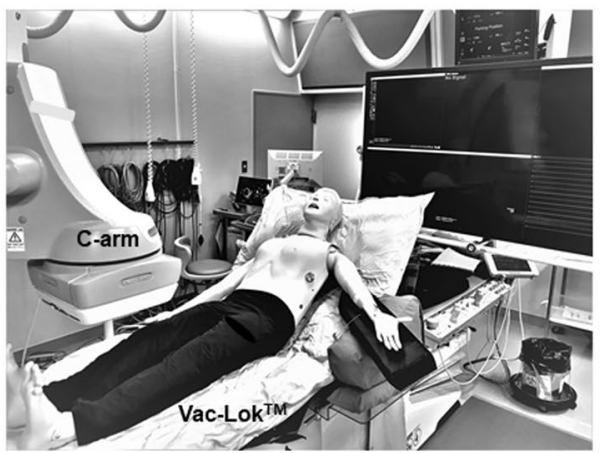

(b)

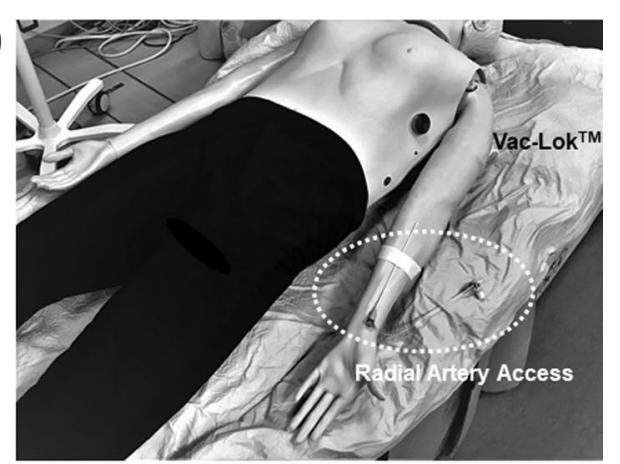

(d)

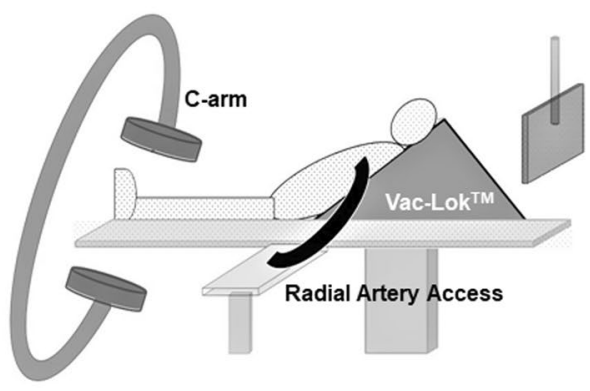

Fig. 1 a Patient lying on the Vac-Lok device in the opposite direction of the C-arm on the X-ray machine. $\mathbf{b}$ Left radial artery as the vessel access site. c Patient's upper body fixed in Fowler's position. $\mathbf{d}$ Schema showing the patient in Fowler's position on the catheterization table during transradial peripheral vascular intervention

and the outer diameter is the same size as that of current 6 Fr sheaths [3]. To position the 7 Fr R2P Glidesheath sheath, a 7 Fr 120-cm long R2P SlenGuide guiding catheter (Terumo, Tokyo, Japan) needs to be inserted into the sheath and advanced to the right or left iliac artery using a 0.035 inch Rafifocus stiff J-shaped $380-\mathrm{cm}$ long guidewire (Terumo, Tokyo, Japan). This guiding catheter also has a thin-walled design and thin inner lumen to accommodate balloons or stents [3]. The 6 Fr R2P Destination slender sheath is relatively new. It has been developed for radial access, and it is specifically designed to have greater flexibility and tracking [5]. The 6 Fr R2P Destination slender sheath needs to be directly advanced into the right or left iliac artery, if possible, and into the femoral artery with a 0.035 inch Rafifocus stiff long guidewire. After the vascular access procedure was completed, the patient's upper body was fixed at a $45^{\circ}$ angle (so-called Fowler's position) with a Vac-Lok fixation device (Fig. 1c, d).

\section{Case 1}

A 75-year-old Japanese female (height: $150 \mathrm{~cm}$; weight: $43 \mathrm{~kg}$ ) was emergently admitted to our hospital for worsening HF due to ischemic cardiomyopathy, with a left ventricular ejection fraction less than $35 \%$. The patient had a medical history of diabetes mellitus and smoking. She had been diagnosed with PAD at 73 years of age, and she underwent amputation surgery above the left knee owing to ischemic and diabetic necrosis 1 year prior. Although her symptoms for HF had improved after resting in Fowler's position and treatment with diuretics, beta blockers, and angiotensin-converting enzyme inhibitors, she complained of rest pain in her right lower leg 1 week after admission. Physical findings showed absent pedal pulses, and shiny smooth, pallor, cold skin of the right leg. The ankle-brachial index (ABI) was unmeasurable at rest. A computed tomography (CT) angiogram showed chronic total occlusion (CTO) of the right superficial femoral artery (SFA) and left external iliac artery (Fig. 3a). She was diagnosed as critical limb ischemia (clinical limb stage: Fontaine III). We decided to perform PVI for revascularization of the right SFA during this hospitalization because of severe pain uncontrolled by pain relief medicines. We considered that she would still need to be in Fowler's position on the catheterization table during PVI to prevent worsening HF. After insertion of a 7 Fr R2P Glidesheath slender sheath and advancement of a 7 Fr 120-cm long SlenGuide catheter into the right iliac artery, the patient was fixed in Fowler's position with the Vac-Lok fixation device (Fig. 2a). 
(a)

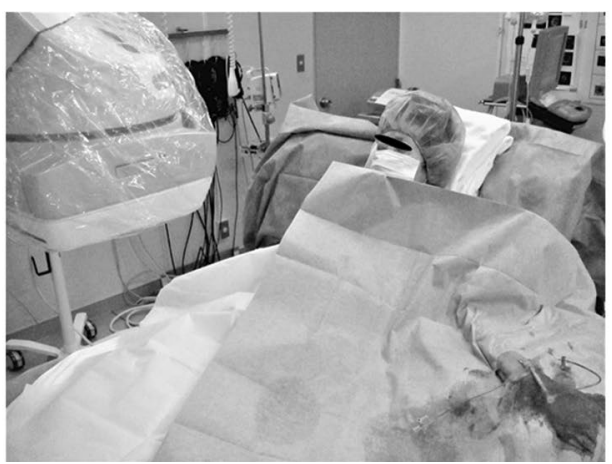

(b)

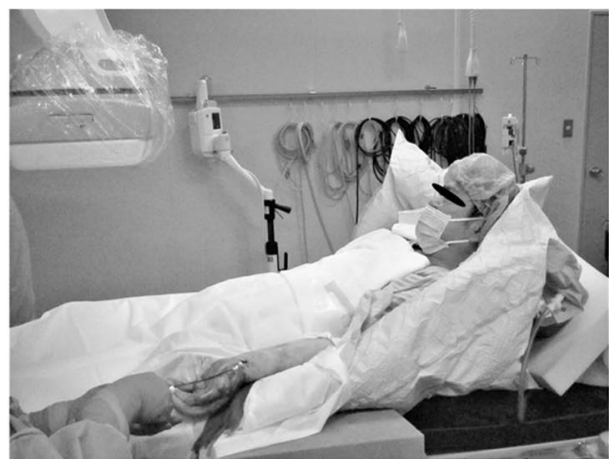

Fig. 2 Case 1 patient $\mathbf{a}$ and case 2 patient $\mathbf{b}$ in Fowler's position during transradial peripheral vascular intervention

(a)

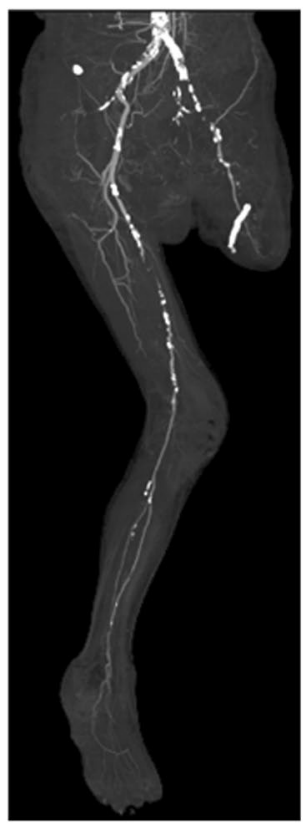

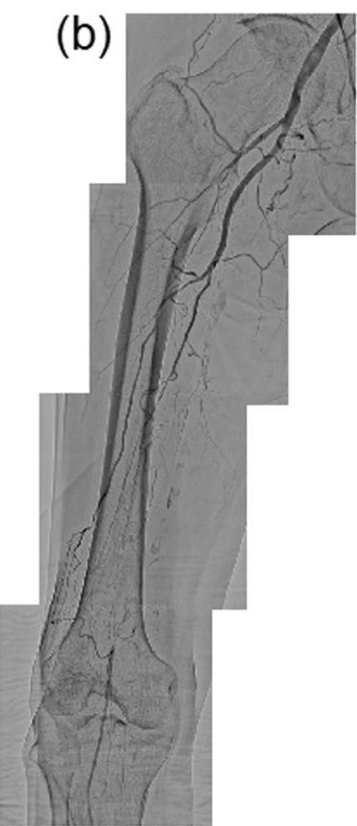

(c)

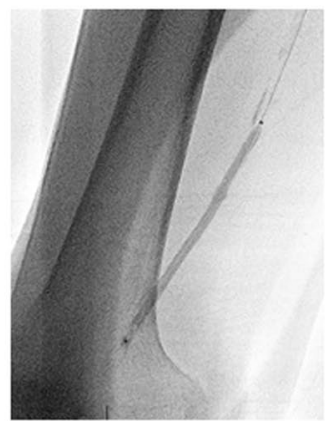

(d)

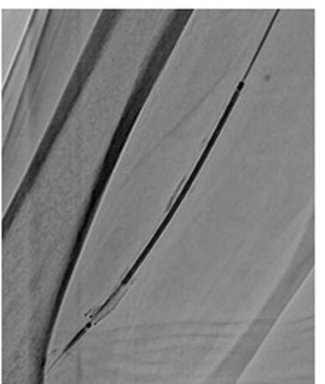

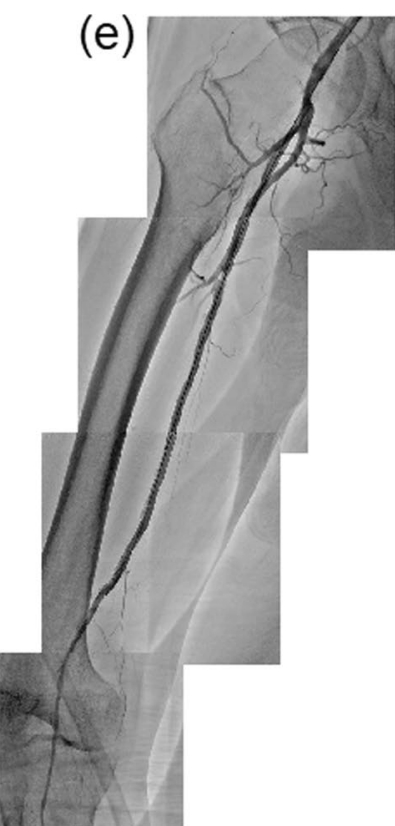

Fig. 3 Computed tomography (CT) angiographic image showing total occlusion of the left superficial femoral artery (SFA) and the left iliac artery (a). Angiography of the right SFA before and after peripheral vascular intervention (PVI), shown in $\mathbf{b}$-e. Initial angiography showing total occlusion of the left SFA from the ostium to the distal portion (b). PVI was performed with balloon inflation c and stent implantation (d). Final angiography after PVI showing a good result (e)

Initial angiography showed total occlusion of the left SFA from the ostium to the distal portion (Fig. 3b). We advanced a 0.014 inch Halberd guidewire (Asahi Intecc, Nagoya, Japan) with a $2.5 \mathrm{Fr} 150-\mathrm{cm}$ long Corsair Armet microcatheter (Asahi Intecc, Nagoya, Japan) into the right SFA. We successfully crossed the wire into the CTO lesion of the right SFA, and we dilated the lesion with a 4.0-100 mm Metacross rapid-exchange balloon catheter (Terumo, Tokyo, Japan) (Fig. 3c). After predilation, we implanted two rapid-exchange $6.0-100 \mathrm{~mm}$ R2P Misago stents (Terumo, Tokyo, Japan) with a $200-\mathrm{cm}$ long shaft system in the CTO lesion of the right SFA (Fig. 3d).
Following postdilation of the stents with a $5.0-100 \mathrm{~mm}$ Metacross balloon catheter, we confirmed favorable blood flow below the right knee without residual stenosis and dissection (Fig. 3e). The guiding sheath in the right iliac artery and the sheath in the left RA were withdrawn and the puncture site was managed via continuous compression using TR Band (Terumo, Tokyo, Japan), a hemostasis device used for transradial catheterization. We did not use vasodilators, and we had no access site-related complications. HF did not worsen during PVI nor in the postoperative period. The ABI had improved to 0.78 in the right leg, and she was discharged 1 week after her 
PVI. At 6 months after PVI, she was completely free from pain in her right lower leg. ABI at rest of the leg maintained a relatively good level (0.72) and chronic HF had been well managed medically.

\section{Case 2}

A 74-year-old Japanese male (height: $161 \mathrm{~cm}$; weight: $56 \mathrm{~kg}$ ) with a medical history of hypertension, dyslipidemia, and smoking was admitted to our hospital for treatment of PAD with a 5-month history of intermittent claudication (Fontaine classification: IIb) in both his lower legs, despite optimal medication. Physical findings showed diminished pedal pulses and cold skin of both legs. The patient's maximum walking distance was about $150 \mathrm{~m}$, and the right and left leg ABI scores at rest were 0.52 and 0.64 with monophasic wave forms, respectively. A CT angiogram showed CTO lesions in the proximal portion of both SFAs (Fig. 4a). Although we decided to intervene on CTO lesions of both SFAs, there were concerns his HF could get worse during PVI. He had a history of two hospitalizations due to hypertensive HF and a worsening HF event during cardiac catheterization. Thus, the patient underwent PVI procedures for SFA CTO lesions on both sides. After successful insertion of a 7 Fr Glidesheath slender sheath into the left RA, the patient was put in Fowler's position using the Vac-Lok fixation device (Fig. 2b). We advanced a 7 Fr 120-cmlong SlenGuide catheter into the right iliac artery, and we tried to advance a 0.014-inch Gladius guidewire (Asahi Intecc, Nagoya, Japan) into the right SFA. Unfortunately, we failed to pass the wire through the CTO lesion in the right SFA due to inadequate backup support by the guiding catheter. To strengthen the backup force during advancement, we removed the guiding catheter from the sheath and exchanged the sheath for a 6 Fr 119-cm long R2P Destination slender sheath. The Destination slender sheath was advanced into the right external iliac artery, and then a 0.014-inch Gladius guidewire (Asahi Intecc, Nagoya, Japan) with a 2.8 Fr 150-cm long Corsair PV microcatheter (Asahi Intec, Nagoya, Japan) was advanced into the right SFA. We managed to cross the wire through the CTO in the right SFA, and we dilated the lesion with a 6.0-200 $\mathrm{mm}$ Crosstella rapid-exchange balloon catheter (Terumo, Tokyo, Japan) (Fig. 4b). After predilation, we implanted three R2P Misago rapid-exchange stents; $6.0-100,60$, and $40 \mathrm{~mm}$, using a $200-\mathrm{cm}$ long shaft system in the CTO lesion in the right SFA (Fig. 4c). Postdilation was done with the same balloon as predilation. Next, we performed endovascular treatment (EVT) for the CTO lesion in the left SFA. We advanced a Destination slender sheath into the left external iliac artery and crossed a 0.014-inch Gladius guidewire with a Corsair
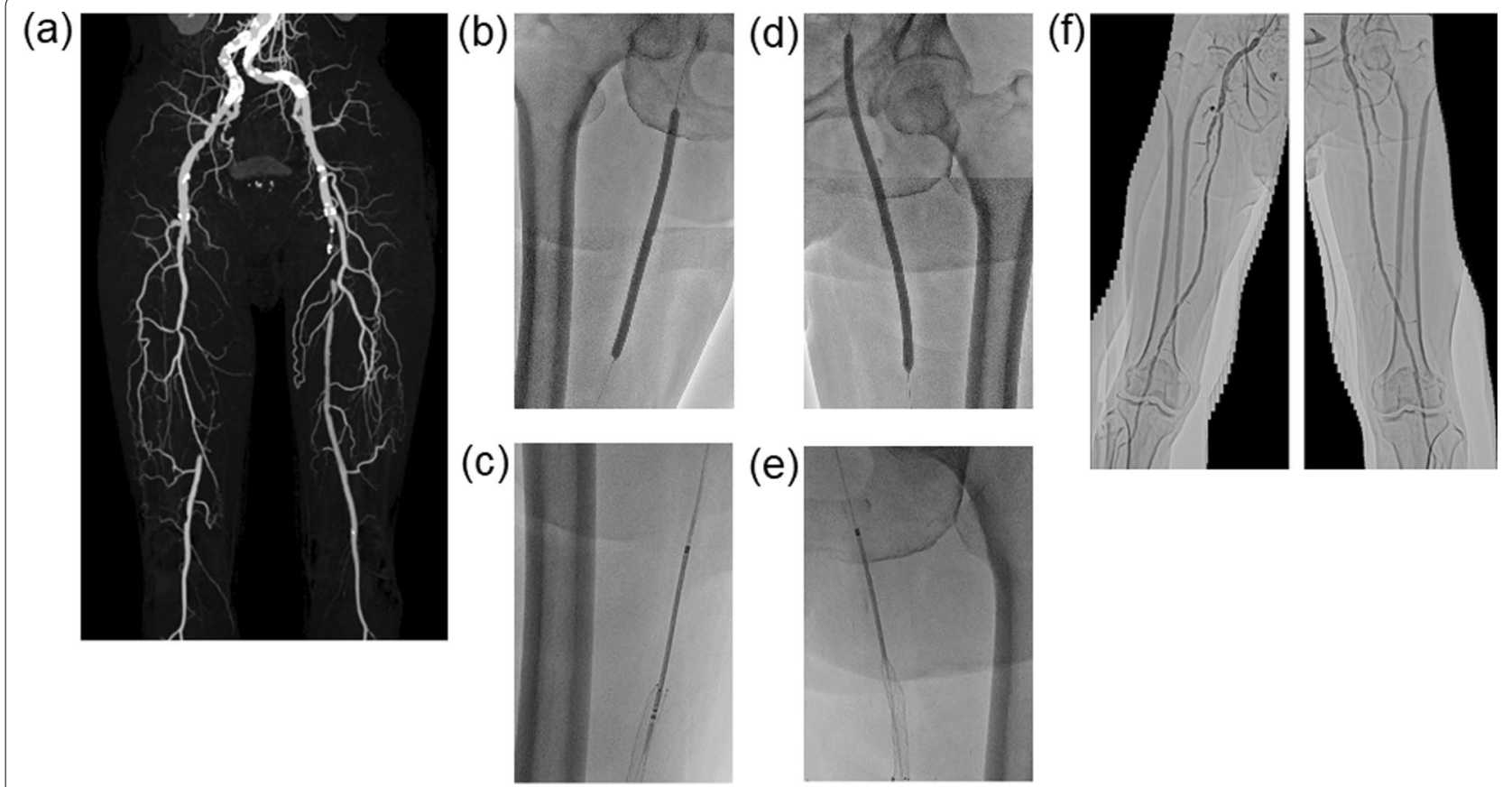

(e)

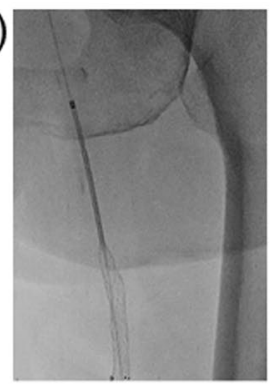

Fig. 4 a Computed tomography (CT) angiographic image showing total occlusion of the right and left superficial femoral artery (SFA): from the ostium to the distal portion in the right SFA; from the ostium to the mid portion in the left SFA. Angiography of the right and left SFA before and after peripheral vascular intervention (PVI), shown in b-f. PVI in the right SFA was performed with balloon inflation $\mathbf{b}$ and stent implantation (c), and that in the left SFA was performed with balloon inflation $\mathbf{d}$ and stent implantation (e). Final angiography after PVI showing good results in both legs $(\mathbf{f})$ 
PV microcatheter through the left SFA. After predilation with a $6.0-200 \mathrm{~mm}$ Crosstella balloon catheter (Fig. 4d), a 7.0-100 mm R2P Misago stent was implanted (Fig. 4e). Postdilation was done with the same balloon as predilation. The final angiography showed no residual stenosis, no dissection, and favorable blood flow in both legs (Fig. 4f). TR Band was used to achieve hemostasis after the sheath was removed from the left RA. We had no access site-related complications. He showed no worsening $\mathrm{HF}$ and complained of no intermittent claudication after the procedure. His ABI improved to 1.00 in the right leg and 1.01 in the left leg. He was discharged 2 days after his PVI. At 12 months after PVI, he was completely free from quality of life-threatening claudication, with good levels of $\mathrm{ABI}$ at rest (right: 0.95; left: 0.98) and chronic HF had been well-managed medically.

\section{Discussion}

We present two cases of PAD patients with HF who underwent transradial endovascular intervention. The patients were placed in Fowler's position on the catheterization table during the PVI procedure in order to avoid worsening congestive HF.

A patient's position plays a vital role in the management of HF, especially to prevent worsening HF [6]. During percutaneous coronary or peripheral intervention, patients are usually put in the supine position on the catheterization table. In this position, venous blood in the abdomen and lower extremities is mobilized, and venous return to the right ventricle increases, further elevating pulmonary venous and capillary pressure. This may result in a patient perceiving dyspnea due to pulmonary edema, with a decrease in pulmonary compliance and an increase in airway resistance $[2,7,8]$. Compared with the supine position, a semi-sitting position can decrease venous return and is more comfortable for patients with HF $[7,8]$. Thus, we put patients in Fowler's position to prevent worsening HF in the intra- and perioperative period.

In our case, the RA was selected as the access site because the patients were positioned with their head and legs reversed on the table. A brachial approach was not considered suitable because it has been linked with higher risk of large hematoma and pseudoaneurysm formation compared with the RA approach [9]. In our case, the Terumo R2P system, which has been developed for transradial peripheral intervention, was used [3]. As shown in case 2, the R2P system with Destination slender sheath seems to have a more powerful back force, compared with the Glidesheath slender sheath and SlenGuide > catheter, in the treatment of long and complex SFA lesions. Although the safety of this system in transradial coronary or peripheral intervention has already been reported [3, 10], Nazir et al. recently reported a case of severe RA spasm, causing entrapment of the Destination slender sheath and requiring emergency surgery for sheath removal [5]. We believe it would be meaningful to develop sheaths smaller in diameter to perform treatment in a less invasive manner; however, at the same time, we need to be aware of potentially serious complications such as vessel hematoma, dissection, major bleeding, and refractory spasms [10].

Body position affects chest wall volume, lung function, and respiratory muscle strength. Spirometric parameters in healthy young patients were reported to be better in Fowler's position than in the supine position [11]. Although further studies are necessary, Fowler's position may also be more comfortable for patients without HF.

\section{Conclusion}

To the best of our knowledge, this is the first report on PVI procedures conducted while patients with HF were in Fowler's position. The left RA approach, implementing the Terumo R2P system was useful for those lying down on the catheterization table in the opposite direction of the X-ray machine. Although device availability limits the RA approach, we believe this is a viable method, at least in patients at risk of worsening HF.

\section{Abbreviations}

HF: Heart failure; PVI: Peripheral vascular interventions; PAD: Peripheral arterial disease; RA: Radial artery; ABI: Ankle-brachial index; CT: Computed tomography; CTO: Chronic total occlusion; SFA: Superficial femoral artery.

\section{Acknowledgements}

The authors would like to thank Enago (www.enago.jp) for English language editing.

\section{Authors' contributions}

AN, KS, and HE performed the PVI procedures and treatment for HF. AN drafted the manuscript and revised it critically for important intellectual content. HE provided final approval of the submitted manuscript. All authors read and approved the final manuscript.

\section{Funding}

No specific grants from any funding agency in the public, commercial, or nonfor-profit sectors were received for this study.

\section{Availability of data and materials}

The data used in the case report are available on reasonable request.

\section{Declarations}

Ethics approval and consent to participate

This study has been reviewed by the institutional review board and the need for ethics approval was waived.

\section{Consent for publication}

Written informed consent was obtained from each patient for publication of this case report and any accompanying images. Copies of the written consents are available for review by the Editor-in-Chief of this journal. 


\section{Competing interests}

The authors have no financial or nonfinancial competing interests to declare.

Received: 19 August 2021 Accepted: 22 December 2021

Published online: 21 January 2022

\section{References}

1. Kubota S, Endo Y, Kubota M, Shigemasa T. Assessment of effects of differences in trunk posture during Fowler's position on hemodynamics and cardiovascular regulation in older and younger subjects. Clin Interv Aging. 2017:12:603-10.

2. Gheorghiade M, Follath F, Ponikowski P, Barsuk JH, Blair JE, Cleland $J G$, et al. Assessing and grading congestion in acute heart failure: a scientific statement from the acute heart failure committee of the heart failure association of the European Society of Cardiology and endorsed by the European Society of Intensive Care Medicine. Eur J Heart Fail. 2010;12(5):423-33.

3. Shinozaki N, Ikari Y. Superficial femoral artery stenting via radial access using R2 ${ }^{\circledR}$ Misago ${ }^{\circledR}$ stents: first-in-human report of the new R2P ${ }^{\circledR}$ system. SAGE Open Med Case Rep. 2019. https://doi.org/10.1177/20503 $13 \times 19847348$

4. Cronin B, McCarthy A, Claire K, Starling P, Deegan T, Owen R, et al. Quality improvement investigation for head and neck stabilization in radiotherapy using setup tattoos. J Med Imaging Radiat Sci. 2013;44(2):92-9.

5. Nazir S, Nesheiwat Z, Syed MA, Gupta R. Severe radial artery spasm causing entrapment of the Terumo radial to peripheral destination slender sheath: a case report. Eur Heart J Case Rep. 2020:4(2):1-4.

6. Akpinr $\mathrm{G}$, Topaçoğlu H. Evaluation of the effect of patient position in the management of chronic heart failure patients presenting with dyspnea. J Surg Med. 2021;5(3):284-8.

7. Martin-Du Pan RC, Benoit R, Girardier L. The role of body position and gravity in the symptoms and treatment of various medical disease. Swiss Med Wkly. 2004;134(37-38):543-51.

8. Vitacca M, Scalvini S, Volterrani M, Paneroni M, Giordano A, Ambrosino N. Physiological and symptom effects of changing posture from sitting to supine, and vice versa, in stable chronic heart failure. Acta Cardiol. 2016;71(5):543-8.

9. Otsuka M, Shiode N, Nakao Y, Ikegami Y, Kobayashi Y, Takeuchi A, et al. Comparison of radial, brachial, and femoral access using hemostatic device for percutaneous coronary intervention. Cardiovasc Interv Ther. 2018;33(1):62-9.

10. Aminian A, Iglesias JF, Van Mieghem C, Zuffi A, Ferrara A, Manih R, et al. First prospective multicenter experience with the 7 French Glidesheath slender for complex transradial coronary intervention. Catheter Cardiovasc Interv. 2016;89(6):1014-20.

11. Pal AK, Tiwari S, Verma DK. Effect of recumbent body positions on dynamic lung function parameters in healthy young subjects. J Clin Diagn Res. 2017. https://doi.org/10.7860/JCDR/2017/25202.9828.

\section{Publisher's Note}

Springer Nature remains neutral with regard to jurisdictional claims in published maps and institutional affiliations.

Ready to submit your research? Choose BMC and benefit from:

- fast, convenient online submission

- thorough peer review by experienced researchers in your field

- rapid publication on acceptance

- support for research data, including large and complex data types

- gold Open Access which fosters wider collaboration and increased citations

- maximum visibility for your research: over $100 \mathrm{M}$ website views per year

At $\mathrm{BMC}$, research is always in progress.

Learn more biomedcentral.com/submissions 